\title{
CUIDANDO DA ROUPINHA DO NENÊ: O FEMININO NA COLEÇÃO BIBLIOTECA DE ORIENTAÇÃO DA PROFESSORA PRIMÁRIA, NO PROGRAMA DE ASSISTÊNCIA BRASILEIRO AMERICANO DE ENSINO ELEMENTAR (PABAEE) SOB A ÓTICA DAS CONTRIBUIÇÕES DE SIMONE DE BEAUVOIR.
}

\author{
Susane da Costa Waschinewski ${ }^{1}$ \\ Giani Rabelo (Professora orientadora) ${ }^{2}$
}

\begin{abstract}
Ninguém nasce mulher: torna-se mulher. Nenhum destino, psíquico, econômico define a forma que a fêmea humana assume no seio da sociedade; é o conjunto da civilização que elabora esse produto intermediário entre o macho e o castrado que qualificam de feminino (Simone de Beauvoir).
\end{abstract}

\section{INTRODUÇÃO}

Este artigo é fruto das discussões realizadas na disciplina de Gênero e Educação: Contribuições de Simone de Beauvoir ofertada pelos Programas de Pós Graduação em Educação (PPGE) e Desenvolvimento Sócio Econômico (PPGDS) na Universidade do Extremo Sul Catarinense (UNESC) no qual dedicou em realizar o estudo da obra de Simone de Beauvoir Segundo Sexo, volume um (1) "Fatos e Mitos" e o volume dois (2) "A Experiência Vivida".

Para esse trabalho a temática escolhida envolve meu objeto de pesquisa no programa do Mestrado em Educação que é a Coleção Biblioteca de Orientação da Professora Primária integrante do Programa de Assistência Brasileiro Americano de Ensino Elementar (PABAEE), tal programa foi firmado entre Brasil e Estados Unidos (EUA) no ano de 1956, pelo então presidente Juscelino Kubitscheck (1956 1961) e o ministro da Educação e Cultura Clóvis Salgado, o programa teve vigência nos anos de 1956 a 1964 e tinha como objetivo a prestação de assistência técnica pelos norte-americanos ao ensino primário brasileiro os quais estavam previstos: a) formar professores do ensino normal, b) elaborar materiais didáticos, c) enviar aos Estados Unidos professores/as de ensino normal e elementar para realizar curso de aperfeiçoamento (PAIVA; PAIXÃO, 2002).

\footnotetext{
${ }_{1}^{1}$ Mestranda no Programa de Pós Graduação em Educação- UNESC - suzane_geo@hotmail.com 2 UNESC - gra@unesc.net
} 
Em relação à elaboração de materiais didáticos, além do amplo acervo construído no Instituto de Educação do Estado de Minas Gerais, local sede do programa, foi elaborada a Coleção Biblioteca de Orientação da professora Primária, e como o próprio nome diz, essa coleção tinha como objetivo orientar a professora primária em suas atividades em sala de aula, proporcionando o aperfeiçoamento técnico por meio das novas metodologias oferecidas nesses manuais e nas formações realizadas pelo convênio. A coleção conta com os seguintes volumes: Ver, sentir, descobrir a Aritmética, de Rizza Araújo Porto; Experiências de Linguagem Oral, de Maria Yvonne Atalécio de Araújo; Formação e desenvolvimento de conceitos, de Maria Luiza de Almeida Couto Ferreira, Testes, medidas e avaliação, de Oyara Petersen Esteves; O que é Jardim de Infância, de Nazira Feres Abi-Sáber; Ciências na Escola Moderna, de Maria José Berutti e Terezinha Nardell e o volume Habilidades de Estudos Sociais, de Maria Onolita Peixoto o qual buscarei como corpus documental para esse trabalho.

Esse estudo tem como objetivo abordar o feminino a partir da análise imagética, compreendendo que as imagens cumprem uma importante função na construção dos papéis de gênero, ancorados na obra de Simone de Beauvoir Sexo, volume um (1) "Fatos e Mitos" e o volume dois (2) "A Experiência Vivida".

\section{METODOLOGIA}

O corpus documental dessa pesquisa foi o volume intitulado Habilidades de Estudos Sociais da Coleção da Professora Primária documento que integra a produção didática do PABAEE, de autoria da professora Maria Onolita Peixoto. A partir de uma apreciação cuidadosa da imagem intitulada Cuidando da Roupinha do nenê, amparei-me nos escritos de Simone de Beauvoir: O Segundo Sexo, volume um (1) "Fatos e Mitos" e o volume dois (2) "A Experiência Vivida".

A metodologia empregada nesse trabalho consiste em uma pesquisa documental, o qual tem como objetivo realizar aproximações com a "realidade" de por meio da análise dos documentos investigados. Segundo Lüdke e André (1986, p. 38), "a análise documental pode se constituir numa técnica valiosa de abordagem de dados qualitativos seja complementando as informações obtidas por outras técnicas, seja desvelando aspectos novos de um tema ou problema". São documentos todas as realizações produzidas pelo homem que se mostram como 
indícios de sua ação e que podem revelar suas ideias, opiniões e formas de atuar e viver (Bravo 1991). Nesse sentido, a análise imagética fornece pistas que permitem aproximações com diferentes contextos, ao utilizar tal recurso procura-se reconstruir aspectos sociais econômicos, políticos e religiosos que possibilitem reconhecer os discursos produzidos em determinado período.

\title{
DISCUTINDO A FAMOSA FRASE
}

A famosa frase de Beauvoir "Ninguém nasce mulher: torna-se mulher" abre as discussões do volume dois (2) "A Experiência Vivida", quando no primeiro capítulo (I) Infância a autora inicia um longo percurso teórico que vai da condição do feminino na infância, a moça, iniciação sexual, lésbica, mulher casada, mãe, vida social, prostitutas e hetairas, da maturidade a velhice, a situação e caráter da mulher, a narcisista, a amorosa, a mística, e a mulher independente.

No entanto, considero a frase um ponto de ligação entre suas duas obras. No volume um (1), Simone de Beauvoir constrói um importante documento para desmistificar e inferioridade da mulher, recorrendo as bases biológicas entre machos e fêmeas, mostrando que as diferenças biológicas entre esses são ínfimas para legitimar qualquer tratamento de inferioridade a mulher, que possa a condicionar a determinado papel social.

Para contrapor os argumentos que supostamente colocam as mulheres como o segundo, sexo Beauvoir lança discussões no campo da psicanálise, contra argumentando a teoria de Sigmund Freud. "Se o método psicanalítico é muitas vezes fecundo, apesar dos erros da teoria, é porque há em toda história singular dados cuja generalidade ninguém nega [...]." (BEAUVOIR, 1980, p.67).

Além da psicanálise, Beauvoir aborda a mulher na História, em que diversos momentos ficou reclusa ao espaço social e destinada a esfera privada, atrelada a maternidade.

\begin{abstract}
A maior maldição que pesa sobre a mulher é estar excluída das expedições guerreiras. Não é dando a vida, é arriscando-a que o homem se ergue acima do animal; eis por que, na humanidade, a superioridade é outorgada não ao sexo que engendra e sim ao que mata. (BEAUVOIR, 1980, p.85).
\end{abstract}

Ao passo em que, nas tribos de caçadores e coletores, as relações eram de igualdade entre os seus membros, assim mulheres e homens dividiam as 
atividades que exigiam força a dominação da natureza, "[...] conta-se que as amazonas mutilavam seus seios, o que significava que, pelo menos durante 0 período de sua vida guerreira recusavam a maternidade". (BEAUVOIR, 1980, p. 82).

O trabalho reprodutivo afastava as mulheres do trabalho fora da esfera doméstica, que acaba ficando confinada a longos períodos a "impotência" diminuindo assim sua capacidade de trabalho. Constituindo assim uma divisão entre "produção" e "reprodução", ao homem são atribuídas as atividades de produção, torna-se livre, a conquista o mundo natural, exerce relação de dominação da natureza e os animais, tornando- se dono e senhor do meio. A mulher cabe o papel da reprodução dos filhos/as, o que constitui, para Simone de Beauvoir, a maternidade como um grande fardo para as mulheres.

No processo de construção do homem como dominador do meio, foi necessário desqualificar a natureza ligando-a ao feminino, considerando-a por muitas vezes pouco desenvolvida, assim os povos tribais que ainda preservam a mística do feminino são largamente considerados civilizações pouco desenvolvidas e atrasadas.

A história mostrou-nos que os homens sempre detiveram todos os poderes concretos; desde os primeiros tempos do patriarcado, julgaram útil manter a mulher em estado de dependência; seus códigos estabeleceram-se contra ela; e assim foi que ela se constituiu concretamente como Outro. (BEAUVOIR, 1980, p. 179).

Nesse percurso, teóricos não tardaram em contribuir para esse entendimento, nesse sentido a autora aponta algumas discussões com posições sexistas contra Aristóteles, Hegel, Rousseu, Comte, Proudhon, Napoleão, Hitler e Pitágoras.

Já na terceira parte do livro no capítulo, Os Mitos, Beauvoir mostra-nos os arquétipos femininos que são construídos em função da relação com macho, esses arquétipos se constituem no campo religioso, social, cultural, mítico, usados na opressão feminina e na construção da mulher como o outro.

"Ninguém nasce mulher, torna-se mulher" é a expressão de sua obra, trata-se de como a posição da mulher como o outro, como segundo sexo foi se constituindo socialmente, a partir das discussões da biologia da mulher. Simone de Beauvoir mostra-nos por meio de suas pesquisas como ocorre a construção da opressão do feminino nos diferentes momentos na vida das mulheres. 
Beauvoir desafiou a sociedade quando lançou sua obra, e continua desafiando, seus escritos são atuais e, ainda, hoje provocam "auê" quando mencionados, como no recente caso da Prova Nacional do Ensino Médio (ENEM, 2015) ${ }^{3}$, em que a famosa frase de Beauvoir fez parte da avaliação no caderno de Ciências Humanas, causando forte repercussão nos setores mais conservadores e nos que desconheciam os estudos da autora. Em contrapartida, grande comemoração dos movimentos feministas brasileiros.

\title{
A IMAGEM DO FEMININO: CUIDANDO DA ROUPINHA DO NENÊ
}

A forma como nascemos por meio do parto, a desmama, as relações de ciúmes quando é chegado um novo integrante a família, são situações/manifestações simultâneas nas meninas como com os meninos. De acordo com pressupostos da psicanálise referidos por Beauvoir (1980), seus desejos e prazeres são os mesmos, tanto na sucção do leite materno como na fase anal. a exaltação do pênis do menino e as menções de orgulho da família sobre o seu sexo, ou o fato da menina ter esse órgão secreto que só se vê invólucro, ela não se visualiza em uma situação de inferioridade diante do masculino.

Não sente essa ausência como uma falha; seu corpo é evidentemente uma plenitude para ela, mas ela se acha situada no mundo de um modo diferente do menino e um conjunto de fatores pode transformar a seus olhos a diferença em inferioridade (BEAUVOIR,1980,p.14).

Ou seja, essa diferença é tida como natural, sem nenhum problema, mas a forma com que as manifestações vão se construindo em torno do pênis e em torno ao órgão escondido da menina e pouco comentado. Para a autora o trauma da desmama irá se distinguir entre meninos e meninas, pelo ato do menino tentar superar a sua desmama fixando-o no pênis, já na menina essa tendência será transferida para o objeto:

\begin{abstract}
A boneca ajuda-a, mas não desempenha tampouco um papel determinante; o menino pode também querer bem a um urso, um polichinelo, nos quais se projeta; é na forma global de suas vidas que cada elemento - pênis, boneca assume sua importância. Assim, a passividade que caracterizará essencialmente a mulher "feminina" é um traço que se desenvolve nela desde os primeiros anos (BEAUVOIR, 1980, p.21).
\end{abstract}

\footnotetext{
${ }^{3}$ O Exame Nacional do Ensino Médio (Enem) é uma prova elaborada pelo Ministério da Educação para verificar o domínio de competências e habilidades dos estudantes que concluíram o ensino médio.
} 
A autora, entretanto, faz um alerta sobre essa passividade, ela não é biológica, nada tem a ver com as diferenças biológicas entre meninos e meninas, e sim impostas, frequentemente, por seus educadores e pela sociedade. Sendo que as construções do feminino e do masculino ocorrem por meio das dinâmicas sociais, só se constroem na relação com o outro.

Segundo Beauvoir (1980), enquanto ao menino é permitido fazer suas experiências, seu aprendizado do mundo, de forma livre, subindo em árvores, enfrentando jogos violentos, lutas desafios e provas, um aprendizado que se dá com o outro, situando questões de sua própria virilidade e colocando a menina em situação de desprezo. Já no caso do feminino, a situação ocorre de forma contrária, há um aprisionamento da esfera do lar, onde ocorre um conflito de sua existência autônoma, pois essa liberdade do aprendizado do seu corpo do mundo da natureza é negada:

\begin{abstract}
Tratam-na como uma boneca viva e recusam-Ihe a liberdade; fecha-se assim um círculo vicioso, pois quanto menos exercer sua liberdade para compreender, apreender e descobrir o mundo que a cerca, menos encontrará nele recursos, menos ousará afirmar-se como sujeito; se a encorajassem a isso, ela poderia manifestar a mesma exuberância viva, a mesma curiosidade, o mesmo espírito de iniciativa, a mesma ousadia que um menino (BEAUVOIR, 1980, p. 22).
\end{abstract}

Assim transformam em objeto e aprisionam no lar e em rituais de boas maneiras, tarefas domésticas, ou seja, ocorrem mecanismos que regulam 0 processo de socialização do feminino, podendo dizer que a castração ocorre nas relações no social e não no biológico. Essa infância está anunciando algo para a juventude, que irá concretizar em alguns aspectos, como, por exemplo, a espera pelo outro, o casamento, os cuidados com a casa. É ainda nessa fase em que "a menina pode compensar a superioridade atual do menino mediante as promessas contidas em seu destino de mulher e que, já nesse momento, realiza em seus jogos" (BEAUVOIR, 1980, p. 24). Ela recebe muito mais informações sobre o casamento, os cuidados com a preparação do alimento, os cuidados com a roupa e a casa.

As brincadeiras ditas femininas se encarregam de transmitir boa parte dessas informações, reproduzem sutilmente às relações do meio em que estão inseridas e, segundo a autora, a boneca pode ser seu filho, com quem ralha e pune e depois consola, pode ser a mãe que assume a dignidade quando o pune. 
Geralmente as brincadeiras excluem a figura do pai, é uma relação de mãe e boneca, mãe com mãe, onde para a menina recai o cuidado com as crianças, cabe à mãe, ao feminino, aprender com os relatos ouvidos, livros lidos, nas imagens, toda a sua pequena experiência de vida, que Ihe preparam para o futuro.

Fato que ilustra a imagem intitulada como "Cuidando da roupinha do nenê", retirada da Coleção da Biblioteca da Professora Primária do volume Habilidades de Estudos Sociais, inserida no contexto sobre atividades de dramatização.

A imagem está inserida em um dos volumes que compõe a Biblioteca de Orientação da professora Primária que fez parte do Programa de assistência Brasileiro - Americano ao Ensino Elementar (PABAEE), implementada no Brasil nos anos que ficaram conhecidos como nacional desenvolvimentista sob o governo do então Presidente da República Juscelino Kubitscheck (1956 a 1961). Durante esses anos, ocorreu a instalação e a consolidação da indústria brasileira. Com o intuito de garantir esse processo de modernização do país, Juscelino apresentou um plano para alcançar o desenvolvimento e fornecer bases para a instalação do setor industrial, sendo então lançado o Plano de Metas, que ficou conhecido como uma das primeiras iniciativas de planejamento do país posto em prática.

Essas mudanças em curso acabaram redimensionando as funções atribuídas a educação no período, pois havia um descompasso entre desenvolvimento econômico e a situação educacional. Para Saviani (1997), com o desenvolvimento do processo de industrialização e urbanização, ocorreram pressões sociais em torno do tema da instrução pública, formulou-se o entendimento do analfabetismo como uma doença, uma vergonha nacional, que deveria ser erradicada, e superada. Nesse contexto que o governo de Juscelino firma o acordo com o EUA dando início ao PABAEE, como tentativa de superação dos índices educacionais, o programa, que contaria com técnicos norte-americanos, tinha como objetivo qualificar as professoras primárias, fornecendo cursos de aperfeiçoamento, enviar ao EUA para especializações e a criação de materiais didáticos como o volume aqui abordado.

A biblioteca de Orientação da Professora Primária traz em suas atividades propostas e em sua escrita a necessidade de civilizar-se, aprender pedir a vez, a falar, respeitar o colega, contendo uma visão que para viver em uma 
sociedade que estava se modernizando, era necessária o indivíduo aprender boas práticas.

Diante do que se convencionou denominar como literatura de civilidade, busca-se compreender a noção de certa experiência do que possa implicar o "conceito de civilizado, no sentido de cultivado, polido ou contido", visando uma internalização das regras dispostas ao que possa oportunizar à formação do bom caráter e à construção das boas maneiras (CECCHIN;CUNHA, 2007, p.2).

Segundo as autoras, as literaturas de civilidade em grande parte tiveram como público alvo as mulheres, eram destinadas desde os cuidados com a casa, filhos, família, instruindo noções de higiene e saúde, a manuais de bons comportamentos e etiqueta. Tais literaturas foram pensadas inicialmente para atuarem no espaço privado e, posteriormente, inseridas no âmbito das literaturas escolarizadas, utilizando o espaço escolar como meio para a propagação das normas de conduta.

Nesse sentido, a Coleção da Biblioteca da Professora Primária consiste de um manual para a professora primária, prescrevendo lições e guiando as professoras no ato de ensinar. Segundo Teive (2008), os manuais dedicados aos professores (as) da escola elementar e aos alunos eram tidos como guias para orientar a implantação do novo método de ensino, além de organizar e selecionar os conteúdos, as matérias são reduzidas, propondo lições curtas e atraentes, e de acordo com os objetos da realidade das crianças.

Ao mesmo tempo em que se previa uma expectativa do que esperar da criança, ser comportado, civilizado, praticar a cortesia com seus colegas. Para Cecchin e Cunha (2007), nos anos de entre 1900 e 1960 quando esse tipo de leitura é praticado na escola, tem o intuito de normatizar comportamentos, internalizar regras e preceitos na formação do bom cidadão que irá contribuir no caráter, e para uma consolidação das práticas de higiene, posto que se firmassem as relações urbanas no cotidiano da população das (principalmente) nas grandes cidades.

Tais manuais se constituem de artefatos que carregam consigo pedagogias que ensinam ser, agir no mundo, como no caso da figura um (1), na qual a menina brinca de passar a roupinha do nenê, constitui na imagem que reproduz as normas e as representações de um modelo de feminino. Nesse processo de educação e representação que vão se construindo práticas que Beauvoir comenta que são muito cedo conhecidas pelas meninas. 
Além dessa esperança que o brinquedo da boneca concretiza a vida caseira fornece também à menina possibilidade de afirmação. Grande parte do trabalho doméstico pode ser realizada por uma menina muito criança; habitualmente dele os meninos são dispensados; mas permite-se, pede-se mesmo à irmã, que varra, tire o pó, limpe os legumes, lave um recémnascido, tome conta da sopa (BEAUVOIR, 1980, p.27).

As diferentes brincadeiras entre meninas e meninos, enquanto os meninos estão na rua exercitando desafios, habilidade que envolve força, resistência, as meninas estão reservadas ao espaço do lar, as brincadeiras que reproduzem as tarefas da mãe, deixam suas bonecas com roupinhas, limpas cheirosinhas, fazem a comidinha, banham e trocam os bebes. Assim vai se determinando os espaços do feminino na sociedade, onde muito provavelmente $o$ homem estará empregado na política, no trabalho fora de casa, no trato braçal como intelectual, a mulher estará segregada ao espaço privado, sendo predestinada ao lar, o casamento, os cuidados com as crianças e os idosos. Assim a imagem da menina que passa a roupinha do nenê remete o pensamento de Beauvoir:

[..] o conforma; encorajam-na a encantar-se com essas riquezas futuras, dão-lhe bonecas para que tais riquezas assumam desde logo um aspecto tangível. Sua "vocação" é-lhe imperiosamente ditada. Pelo fato de a criança se lhe apresentar como seu quinhão, pelo fato também de se interessar mais do que o menino pelos seus "interiores", a menina mostra-se mais particularmente curiosa do mistério da procriação (BEAUVOIR, 1980, p.24).

Confinada e vigiada a riqueza de seu futuro está na transformação da boneca em criança, das roupinhas de brincar em roupas de verdade, da espera do príncipe encantado ao casamento, construindo a vocação do feminino, da maternidade. Nessa situação não se imagina responsável por seu próprio futuro, a inferioridade vai se constituindo, num processo onde a mulher é tutelada, antes sob a posse do pai e depois a do marido, onde a maternidade exprime o aspecto de vocação.

\section{CONSIDERAÇÕES FINAIS}

Vivemos na mediação de construção de um com o outro num processo das relações sociais, culturais e históricas nesse movimento produzimos artefatos ${ }^{4}$

\footnotetext{
${ }^{4}$ Um artefato cultural, segundo Paul Du Gay (1997, p.5), é algo que possui um conjunto particular de significados e práticas culturais em torno dele. São conceitos construídos em torno de um objeto, de uma produção cinematográfica, de um tipo de sapato, de uma boneca, de um aparelho eletrônico ou em torno de campos conceituais mais amplos como infância, maternidade, educação. Segundo o autor: Os artefatos culturais pertencem à nossa cultura porque construímos um pequeno mundo de
} 
que estão empregados com a forma com que vivemos e enxergamos o mundo. Como as imagens, que agem sobre nós, constroem visões e entendimentos de mundo, podendo reforçar ou desconstruir as relações sobre qualquer assunto, inclusive entre as relações de feminino e masculino.

\begin{abstract}
Apesar das imagens visuais terem se transformado num dos meios mais persuasivos de comunicação no último século, as escolas têm ignorado solenemente seu enorme poder social, histórico e cultural como um texto cultural. Ainda assim, as imagens visuais e as experiências de ver e ser visto saturam os espaços públicos e privados, influenciando a forma como as crianças, os adolescentes e os professores aprendem, agem ou transformam suas identidades, valores e comportamentos (PAULY, 2003, p. 264).
\end{abstract}

As imagens sejam da menina passando a roupinha, seja do menino brincando de bola, se articula e constroem significados, reforça papeis do que vem a se convencionar serem masculinas e femininas essas imagens circulam em vários ambientes, desde anúncios publicitários, aos materiais didáticos, como visto na imagem analisada.

Quando encontradas nos manuais escolares devem ser problematizadas com os alunos/as, possibilitando um espaço de reflexão sobre a construção dos papeis ditos femininos e masculinos.

Ao tomar a obra de Simone de Beauvoir como base para essa discussão, se fez uma escolha teórica por compreender a importância e relevância de sua pesquisa, embora a autora se dedique ao estudo da mulher, em sua celebre frase Ninguém nasce mulher: torna-se mulher "Creio que aí reside a manifestação primeira do conceito de gênero. Ou seja, é preciso aprender a ser mulher, uma vez que o feminino não é dado pela biologia, ou mais simplesmente pela anatomia, e sim construído pela sociedade." (SAFFIOTI, p.160). Compreendo que embora não tenha discutido a categoria gênero, Simone de Beauvoir nos faz refletir não só para o feminino, mas para o jogo de relações entre feminino e masculino, onde um se constrói na relação com o outro.

Ao se dedicar estudar a mulher coloca que essa construção do feminino, ocorre com grande ênfase na educação feminina que por muito tempo ocorrem por meio de amigas, professoras, vivendo entre matronas como no tempo do gineceu,

significados e este associar o objeto aos significados é que faz dele um "artefato cultural". (CUNHA, 2005). 
escolhem para ela livros e jogos que a prepare para seu destino, revelam-lhes os tesouros de sabedoria feminina, nos ritos ensinam a cozinhar, a costurar, a cuidar da casa ao mesmo tempo da arte de seduzir, do pudor; vestem-na com roupas incômodas e preciosas de que precisa tratar, penteiam-na de maneira complicada, impõem-Ihe regras de comportamento (BEAUVOIR, 1980, p.24).

Ao crescer percebe as promessas contidas na educação feminina, não a colocará mais em uma posição de superioridade como quando era criança, ao conhecer e tiver mais acesso as informações sobre o casamento e o corpo. Agora percebe um mister da superioridade masculina e a vocação de ser mãe.

Nesse sentido os Manuais de lições e/ou Manuais das professoras se constituíram na ceara da educação destinado ao feminino. Embora o material empírico que consta a imagem abordada nesse estudo não seja destinado aos alunos/as, e sim a professora é possível observar a forma como foi escrito, destinado ao feminino, em um dialogo direto com a professora primária, além do molde dos bons costumes, relacionando-se com os estudos e a construção do feminino apontado por Beauvoir onde cabe a mulher ser educada, recatada para que com seu marido, não demostrar qualquer prazer, praticar a cortesia com os outros, considerar o lar como espaço da mulher e como vocação assim como a maternidade.

\section{REFERÊNCIAS}

BEAUVOIR, Simone de. O Segundo Sexo: A experiência Vivida. Rio de Janeiro: Nova Fronteira, 1980.

CECCHIN, Cristiane, CUNHA, Maria Teresa Santos. Tenha Modos! Educação e sociabilidades em manuais de civilidade e etiqueta (1900-1960). XI Simpósio Internacional Processo Civilizador, Campinas, São Paulo, Brasil, 2007.

CUNHA, Susana Rangel. As infâncias nas tramas da cultura visual. In: MARTINS, Raimundo; TOURINHO, Irene (Orgs.). Cultura visual e infância: quando as imagens invadem a escola... Santa Maria: Editora UFSM, 2010.

PAIVA, Edil Vasconcellos de e PAIXÃO, Lea Pinheiro. PABAEE (1956 - 1964): a americanização do ensino elementar no Brasil? Niterói: EdUFF, 2002. 
PAULY, Nancy. Interpreting Visual Culture as cultural narratives in teacher education. Studies in Art Education: A Journal of issues and research. Arizona: 44(3), p. 264-284, 2003.

SAFFIOTI, Heleieth I B. Primórdios do conceito de gênero. Cadernos Pagu, 12, p.157-163, 1999. Disponível em: <http://www.pagu.unicamp.br/en/simone-beauvoiros-feminismos-seculo-xx-1999-12>. Acesso em: 15 dez. 2015.

SAVIANI, D. A nova lei da educação: trajetória, limites e perspectivas. Campinas: Autores Associados, 1997.

TEIVE, Gladys Mary Ghizoni. Uma Vez Normalista, Sempre Normalista Cultura Escolar e Produção de um Habitus Pedagógico (Escola Normal Catarinense 1911-1935). Florianópolis: Insular, 2008. 